\title{
THE MECHANISM OF THE Cd(II) REDUCTION IN $1 M$ FLUORIDE, PERCHLORATE AND CHLORIDE SOLUTIONS AT THE DME, A COMBINED DC, AC ADMITTANCE AND DEMODULATION STUDY
}

\author{
J. STRUIJS, M. SLUYTERS-REHBACH and J.H. SLUYTERS \\ Van 't Hoff Laboratory of Physical and Colloid Chemistry, State University Utrecht, Padualaan 8, \\ 3584 CH Utrecht (The Netherlands)
}

(Received 22nd December 1984; in revised form 6th February 1984)

\section{ABSTRACT}

On the basis of a recently published theoretical approach further proof is given for the CEE mechanism proposed earlier for the Cd(II) reduction in fluoride solution. It is shown that in perchlorate base electrolyte solution the same mechanism applies and that the rate constant of the chemical step is quite close to the value in fluoride solution.

The theories available at present are found not to apply to the $\mathrm{Cd}(\mathrm{II})$ reduction in chloride solution because of the invalidity of the Randles equivalent circuit, contrary to experimental evidence published so far.

The outstanding potentialities of the demodulation method for the study of charge-transfer mechanisms is clearly demonstrated by means of the systems mentioned.

\section{(I) INTRODUCTION}

Since the invention of polarography, the reduction of $\mathrm{Cd}(\mathrm{II})$ on a mercury cathode has been intensively studied both in order to obtain experimental proof of theories on electrode kinetics and to demonstrate the value of experimental techniques. As a result, there is available at present a large number of kinetic parameters, i.e. standard rate constants and transfer coefficients, obtained by different methods and in different laboratories [1,2]. Almost all of these data have been obtained on the supposition that the kinetics of the reduction obeys the Butler-Volmer equation. In a more limited number of papers the possibility of a complex mechanism, i.e. two consecutive one-electron transfers and the occurrence of a dismutation step, has been discussed [3-6].

Recently [6], from ac work the precision of which allowed the study of the Cd(II) reduction in an unusually large potential range, we were able to demonstrate that in a $1 M \mathrm{KF}$ base electrolyte the existence of a preceding heterogeneous chemical step, followed by two one-electron transfers, must be assumed. Although this mechanism gave the best agreement with the experimental data, unfortunately the possible validity of a totally different mechanism comprising a dismutation step could not be definitely ruled out. 
In the preceding theoretical study [7] we pointed out the effectiveness of the demodulation method developed in our laboratory [8,9], with respect to discrimination between reaction mechanisms with linear and non-linear stoichiometry. The essentials were shown to be inherent in the information comprised in a typical second-order cell response like demodulation, complementing the information obtained from the typical first-order ac admittance method. Moreover, the demodulation method is particularly suitable to be performed with a perturbing signal of high frequency, thus enlarging the dynamic range within which rate constants are detectable. In this paper we wish to show that by means of the demodulation method a decision between the two mechanisms for the reduction of $\mathrm{Cd}(\mathrm{II})$ in $1 \mathrm{M}$ $\mathrm{KF}$ can be made quite clearly, and that it even leads to a refinement of the model proposed by Bongenaar et al. [6].

From the complex formation of $\mathrm{Cd}(\mathrm{II})$ ions with $\mathrm{F}^{-}$ions it can be concluded that in aqueous solution a relatively strong interaction exists between these ions. It could be inferred, therefore, that the heterogeneous chemical step preceding the first electron transfer is the dissociation, at the electrode surface, of some $\mathrm{Cd} \mathrm{F}_{\mathrm{x}}^{2-x}$ species to give a more electroactive state. However, it will be shown that a preceding step with a rate constant of similar magnitude also exists in the case of a $0.5 \mathrm{M}$ $\mathrm{NaClO}_{4}+0.5 \mathrm{M} \mathrm{HClO}_{4}$ supported electrolyte. The combination of admittance and demodulation measurements will prove to be requisite for this system.

In the case of demodulation experiments on the Cd(II) reduction in $1 \mathrm{M} \mathrm{KCl}$ solution, the dimensionless parameter $S_{\mathrm{F}}^{*}[7]$ is found to be in disagreement with the theoretical expressions derived so far: at extreme potentials $S_{\mathrm{F}}^{*}$ exceeds the theoretical limits of +0.5 and -0.5 . This result indicates the invalidity of earlier results obtained for this system assuming the applicability of the Randles circuit $[5,6,10]$.

\section{(II) EXPERIMENTAL}

\section{(II.1) General}

The experiments were performed at $25.0 \pm 0.1^{\circ} \mathrm{C}$ in a three-electrode cell with a DME, a mercury pool counter electrode and a saturated calomel electrode connected with the cell via a salt bridge filled with the supporting electrolyte. In the case of perchlorate solutions a sodium-chloride-saturated calomel electrode (SSCE) was used.

Solutions were prepared from freshly double-distilled water and analytical-grade reagents. The sodium perchlorate solutions were prepared from ultrex sodium carbonate and perchloric acid. Oxygen was removed by bubbling argon freed from traces of oxygen by a B.T.S. catalyst.

The following values of the diffusion coefficients and half-wave potentials were selected from the literature [5,6]: $D_{\mathrm{R}}=10.7 \times 10^{-6} \mathrm{~cm}^{2} \mathrm{~s}^{-1}$; in $1 \mathrm{MKF} D_{\mathrm{O}}=8 \times$ $10^{-6} \mathrm{~cm}^{2} \mathrm{~s}^{-1}, E_{1 / 2}^{\mathrm{r}}=-0.609 \mathrm{~V}$ vs. SCE; in $1 M \mathrm{KCL} D_{\mathrm{O}}=9 \times 10^{-6} \mathrm{~cm}^{2} \mathrm{~s}^{-1}$, $E_{1 / 2}^{\mathrm{r}}=-0.638 \mathrm{~V}$ vs. SCE.

In $0.5 \mathrm{M} \mathrm{NaClO}_{4}+0.5 \mathrm{M} \mathrm{HClO}_{4}$ solution the values $E_{1 / 2}^{\mathrm{r}}=-0.567$ vs. SSCE 
and $D_{\mathrm{O}}=7 \times 10^{-6} \mathrm{~cm}^{2} \mathrm{~s}^{-1}$ were obtained from dc polarograms taking the sphericity of the electrode into account.

\section{(II.2) The faradaic admittance method}

The ac measurements were performed as usual with the network analyser system described earlier [11]. The values of the double layer capacitance $C_{\mathrm{d}}$ in the supporting electrolyte were also measured with this instrument at $1 \mathrm{kHz}$ and at potential intervals of $3 \mathrm{mV}$. These values were fitted to a polynomial of high order to allow accurate interpolation. The experimental accuracy amounted to about $0.5 \%$. The resulting $C_{\mathrm{d}}$ vs. $E$ curves are shown in Fig. 1.

\section{(II.3) The demodulation method}

The modulation polarograms were measured with the instrument described earlier $[9,12]$. All measurements were performed at $\nu_{\mathrm{L}}=\omega_{\mathrm{L}} / 2 \pi=122 \mathrm{~Hz}$ and $\nu_{\mathrm{H}}=\omega_{\mathrm{H}} / 2 \pi$ $=100 \mathrm{kHz}$. The amplitude of the ac current density was kept at $0.24 \mathrm{~A} \mathrm{~cm}^{-2}$ throughout to allow comparison of the raw data in the three base electrolytes

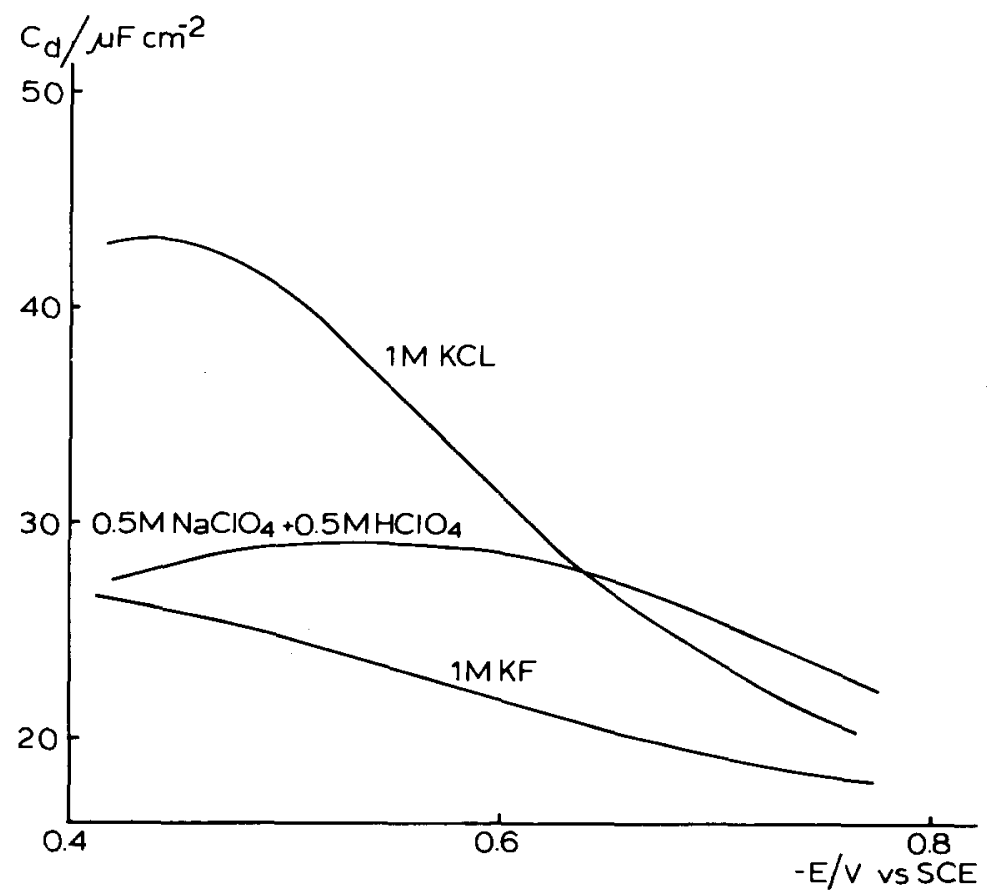

Fig. 1. Double layer capacity of the DME in solutions of $1 \mathrm{M} \mathrm{KF}, 0.5 \mathrm{M} \mathrm{NaClO}_{4}+0.5 \mathrm{M} \mathrm{HClO}_{4}$, and 1 $M \mathrm{KCl}$, measured at $1 \mathrm{kHz}$ at potential intervals of $3 \mathrm{mV}$. Curves obtained by fitting to a polynomial of maximum 20 order. 
studied, viz. $1 M \mathrm{KF}, 1 \mathrm{M} \mathrm{KCl}$ and $0.5 \mathrm{M} \mathrm{NaClO}_{4}+0.5 M \mathrm{HClO}_{4}$. The absence of interfering fourth-order response was ascertained in all cases in the way previously described [12].

\section{(III) DATA ANALYSIS}

For the analysis it was assumed throughout that the systems obey Randles behaviour, i.e. that the premises postulated in the foregoing paper [7] are valid.

Since the reduction of $\mathrm{Cd}$ (II) from the three supporting electrolytes envisaged is relatively fast, the essential parameter $p^{\prime}=R_{\mathrm{ct}} / \sigma\left(R_{\mathrm{ct}}=\right.$ charge transfer resistance, $\sigma=$ Warburg coefficient) is readily obtained from the ac admittance data, using the relationship

$$
Y=Y^{\prime}+i Y^{\prime \prime}=\frac{\omega^{1 / 2}}{\sigma} \frac{(p+1)+i}{(p+1)^{2}+1}+i \omega C_{\mathrm{d}}
$$

where $p=p^{\prime} \omega^{1 / 2}$ and $C_{\mathrm{d}}$ is the double layer capacity.

The potential dependence of $p^{\prime}$ was further analysed in view of its relationship to the rate constant $k_{\mathrm{f}}$ or to the "formal rate constant" $k_{\mathrm{ff}}$ pertaining to a certain reaction mechanism as discussed in ref. 7 . In other words, the quantity

$p^{\prime}[1+\exp (\zeta)]\left(2 D_{\mathrm{O}}\right)^{-1 / 2}=k_{\mathrm{f}}^{-1}$ or $k_{\mathrm{ff}}^{-1}$

was calculated, where

$\exp (\zeta)=\left(D_{\mathrm{O}} / D_{\mathrm{R}}\right)^{1 / 2} \exp \left[(n F / R T)\left(E-E^{\circ}\right)\right]$

The demodulation results are obtained in terms of the quantities $I_{\mathrm{LF}}$ and $Q_{\mathrm{LF}}$, constituting the in-phase and the quadrature components of the demodulation voltage [9]. For a first qualitative comparison of the data from the three different systems it should be realized that both $I_{\mathrm{LF}}$ and $Q_{\mathrm{LF}}$ are proportional to $\left(j_{\mathrm{A}} / 2 \omega_{\mathrm{H}} C_{\mathrm{d}}\right)^{2}$, where $C_{\mathrm{d}}$ is given in Fig. 1. Further analysis was always performed in two ways:

(a) Direct fitting of $I_{\mathrm{LF}}$ and $Q_{\mathrm{LF}}$ to the kinetic parameters of a particular reaction mechanism, using the expressions $[9,12]$

$I_{\mathrm{LF}}-\left[S_{\mathrm{c}}\right]=\left\{\left[S_{\mathrm{F}}\right]-\left[S_{\mathrm{c}}\right]\right\} \frac{a_{\mathrm{L}}^{*}\left(a_{\mathrm{L}}^{*}+1\right)}{\left(p_{\mathrm{L}}+1\right)^{2}+\left(a_{\mathrm{L}}^{*}+1\right)}$
$Q_{\mathrm{LF}}=\left\{\left[S_{\mathrm{F}}\right]-\left[S_{\mathrm{c}}\right]\right\} \frac{a_{\mathrm{L}}^{*}\left(p_{\mathrm{L}}+1\right)}{\left(p_{\mathrm{L}}+1\right)^{2}+\left(a_{\mathrm{L}}^{*}+1\right)^{2}}$

where $p_{\mathrm{L}}=p^{\prime}\left(2 \omega_{\mathrm{L}}\right)^{1 / 2}$ and $a_{\mathrm{L}}^{*}=\left(2 \omega_{\mathrm{L}}\right)^{-1 / 2} \sigma^{-1}\left(C_{\mathrm{d}}+\mathrm{A}^{-1} C_{\mathrm{ex}}\right)^{-1}$ [12]. The value of the capacitive "virtual voltage source" $\left[S_{\mathrm{c}}\right]$ was calculated numerically from the measured $C_{\mathrm{d}}$ values (ref. 9a eqns. (19) and (21)) and the faradaic "virtual voltage source" $\left[S_{\mathrm{F}}\right]$ was adapted to the appropriate model following the theoretical predictions previously derived $[7,9]$. 
(b) Combination of the admittance data and the demodulation data to calculate the quantity $S_{\mathrm{F}}^{*}$ via $[7,9]$

$$
\left\{I_{\mathrm{LF}}-Q_{\mathrm{LF}} \frac{Y_{\mathrm{L}}^{\prime \prime}+Y_{\mathrm{e}}^{\prime \prime}}{Y_{\mathrm{L}}^{\prime}}\right\}\left(\frac{2 \omega_{H} C_{\mathrm{d}}}{j_{\mathrm{A}}}\right)^{2} \frac{R T}{n F}=S_{\mathrm{F}}^{*}
$$

where $Y_{\mathrm{L}}^{\prime}$ and $Y_{\mathrm{L}}^{\prime \prime}$ are the admittance components at twice the low frequency, i.e. 244 $\mathrm{Hz}$, and $Y^{\prime \prime}=2 \omega_{\mathrm{L}} C_{\mathrm{ex}} A^{-1}$ gives the correction for the external capacity in the measuring circuit.

The resulting values of $S_{\mathrm{F}}^{*}$ as a function of dc potential were compared with the theoretical expressions derived for several models [7].

At first sight it seems that these two routes are in fact identical. However, it was found that the $I_{\mathrm{LF}}$ and $Q_{\mathrm{LF}}$ data exhibit a better sensitivity to the kinetic parameters in the potential range around the half-wave potential, whereas $S_{\mathrm{F}}^{*}$ is more discriminating at extreme potentials.

In various stages of the analysis it is necessary to insert precalculated values of the Warburg coefficient $\sigma$. For the systems investigated here it is justified to neglect the influence of the rate constant on the $\sigma$-value at any potential. On the other hand, it is worth emphasizing that accounting for the influence of spherical diffusion is indispensable. So, for the DME with drop time $t$ and drop radius $r_{0}$, we employed the following expression [6]

$\sigma=\frac{R T}{n^{2} F^{2}\left(2 D_{\mathrm{O}}\right)^{1 / 2} C_{\mathrm{O}}^{*}}\left[\exp (\zeta)+1+r_{\mathrm{s}}+r_{\mathrm{s}} \exp (-\zeta)\right]$

with

$r_{\mathrm{s}}=\left[1-1.03\left(t D_{\mathrm{O}}\right)^{1 / 2} r_{0}^{-1}\right] /\left[1+1.03\left(t D_{\mathrm{R}}\right)^{1 / 2} r_{0}^{-1}\right]$

corresponding to the result of a derivation given by Newman [13]. For common values of $D_{\mathrm{O}}, D_{\mathrm{R}}, t$ and $r_{0}$ the sphericity correction factor $r_{\mathrm{s}}$ amounts to ca. 0.8 . It is easily seen that neglect of sphericity, i.e. $r_{\mathrm{s}}=1$, causes errors of $0 \%$ at $E \gg E_{1 / 2}^{\mathrm{r}}, 10 \%$ at $E \approx E_{1 / 2}^{\mathrm{r}}$ and $20 \%$ at $E \ll E_{1 / 2}^{\mathrm{r}}$.

Strictly speaking, curvature of the interface also has an effect on the diffusion impedance itself, i.e. the Warburg impedance should be replaced by a more sophisticated equivalent [14]. In the case of fast reactions neglect of this factor will introduce a systematic error into the evaluation of a rate constant [15]. We did not account for this effect, because it is probably not significant for the systems studied here.

(IV) RESULTS

(IV.I) $C d(I I)$ in $1 \mathrm{M} \mathrm{KF}$

The dots in Figs. 2a, $2 \mathrm{~b}$ and 3 represent the experimental values of $I_{\mathrm{LF}}, Q_{\mathrm{LF}}$ and $S_{\mathrm{F}}^{*}$, respectively. The asymmetry of these curves with respect to $E_{1 / 2}^{\mathrm{r}}(-0.609 \mathrm{~V}$ vs. 

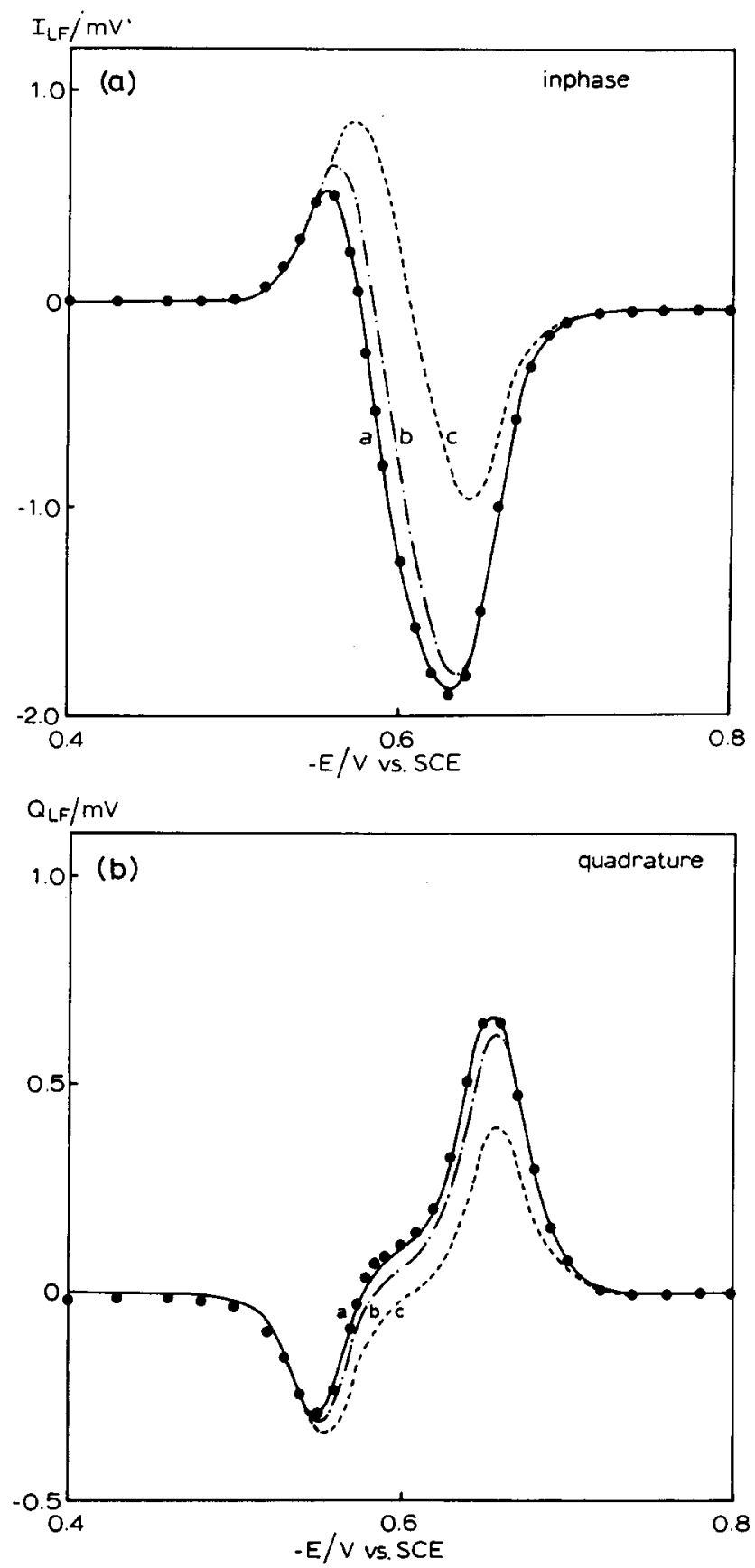

Fig. 2. Components of the demodulation voltage response for $1 \mathrm{~m} M \mathrm{Cd}(\mathrm{II})$ in $1 M \mathrm{KF}$. (a) In-phase component; (b) quadrature component. ( $\bullet$ ) experimental; curves: theoretical for mechanisms and kinetic parameters as summarized in Table 1. Input parameters $\nu_{\mathrm{H}}=100 \mathrm{kHz}, \nu_{\mathrm{L}}=122 \mathrm{~Hz}, j_{\mathrm{A}}=0.24 \mathrm{~A} \mathrm{~cm}^{-2}$. 


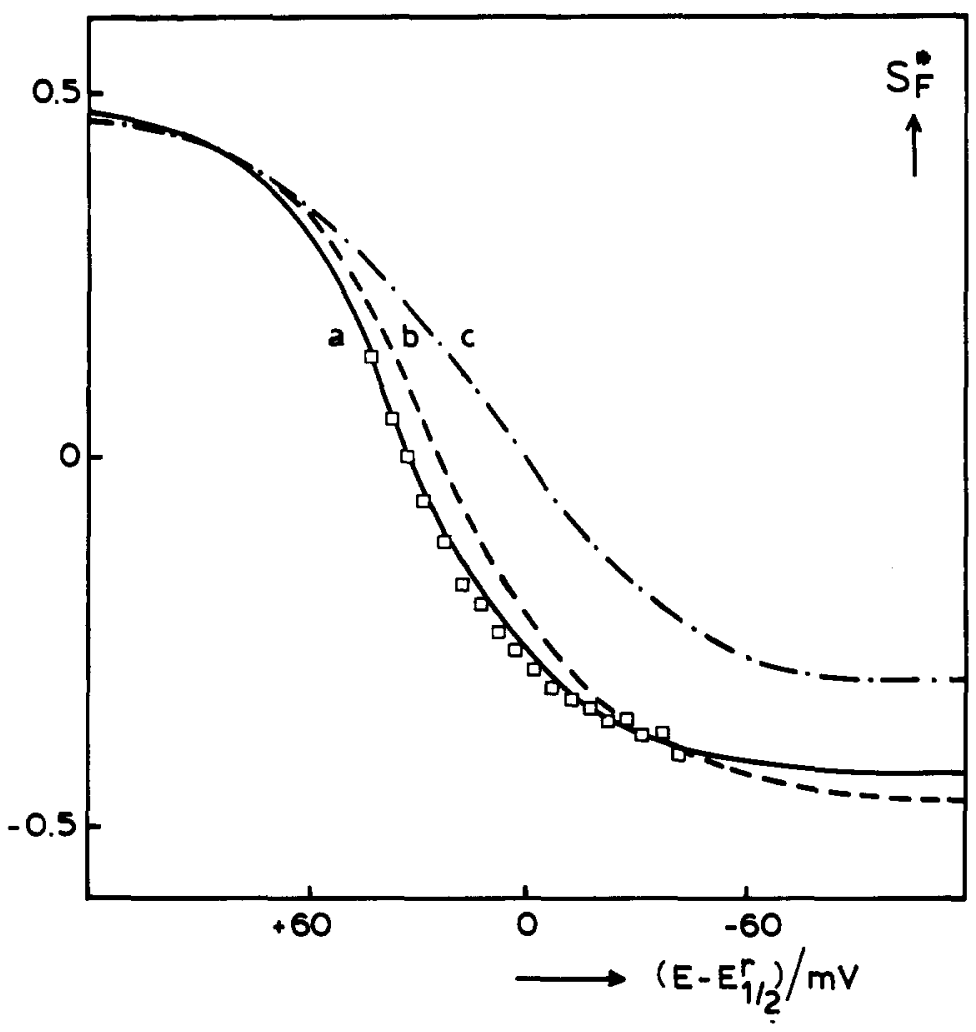

Fig. 3. $S_{\mathrm{F}}^{*}$ as a function of $E-E_{1 / 2}^{\mathrm{r}}$ derived from the data in Fig. 2 and the interfacial admittances $Y=Y^{\prime}+i Y^{\prime \prime}$ at $244 \mathrm{~Hz}$. See text.

SCE) is striking: $S_{\mathrm{F}}^{*}=0$ at $E-E_{1 / 2}^{\mathrm{r}}=32 \mathrm{mV}$ and $S_{\mathrm{F}}^{*}=-0.3$ at $E=E_{1 / 2}^{\mathrm{r}}$, and both in $I_{\mathrm{LF}}$ and $Q_{\mathrm{LF}}$ the anodic peak is much smaller than the cathodic peak. In terms of Butler-Volmer behaviour this indicates that the transfer coefficient is extremely small. However, it turns out to be impossible to fit the data to a Butler-Volmer equation, i.e. with potential-independent transfer coefficient.

The reaction mechanism proposed by Bongenaar et al. [6] as the most probable one for the reduction of $\mathrm{Cd}(\mathrm{II})$ consists of two separate electron-transfer steps preceded by a "chemical" heterogeneous conversion of the $\mathrm{Cd}(\mathrm{II})$ :

$\begin{array}{llll}\mathrm{Cd}(\mathrm{II}) & \stackrel{k_{\mathrm{c}}}{\rightleftarrows} & \mathrm{Cd}(\mathrm{II})^{*} & \mathrm{R}_{\mathrm{c}} \\ \mathrm{Cd}(\mathrm{II})^{*} & +e^{-\stackrel{k_{1}}{\rightleftarrows}} & \mathrm{Cd}(\mathrm{I}) & \mathrm{R}_{1} \\ \mathrm{Cd}(\mathrm{I}) & +e^{-} \stackrel{k_{2}}{\rightleftarrows} & \mathrm{Cd}(\mathrm{Hg}) & \mathrm{R}_{2}\end{array}$


TABLE 1

Kinetic parameters for the reduction of $\mathrm{Cd}(\mathrm{II})$ from $1 M \mathrm{KF}$, according to different mechanisms (see text)

\begin{tabular}{ll}
\hline (a) eqn. (8) + eqn. $(10)$, with chemical step potential-independent \\
$k_{\mathrm{c}}^{0}=0.67 \mathrm{~cm} \mathrm{~s}^{-1}$ & $\alpha_{0}=0$ \\
$k_{s, 1}=0.35 \mathrm{~cm} \mathrm{~s}^{-1}$ & $\alpha_{1}=0.5$ \\
$k_{s, 2}=1.8 \mathrm{~cm} \mathrm{~s}^{-1}$ & $\alpha_{2}=0.6$
\end{tabular}

(b) eqn. (8) + eqn. (10), with chemical step potential-dependent

$k_{c}^{0}=0.33 \mathrm{~cm} \mathrm{~s}^{-1}$

$k_{s, 1}=0.4 \mathrm{~cm} \mathrm{~s}^{-1}$

$\alpha_{0}=0.06$

$k_{s, 2}=1.8 \mathrm{~cm} \mathrm{~s}^{-1}$

$\alpha_{1}=0.5$

$\alpha_{2}=0.6$

(c) eqn. (II) + eqn. (12)

$k_{c, 1}=0.85 \mathrm{~cm} \mathrm{~s}^{-1}$

$k_{s, 1}=5 \mathrm{~cm} \mathrm{~s}^{-1}$

$k_{c, 2}=1.1 \mathrm{~cm} \mathrm{~s}^{-1}$

$\alpha_{1}=0.5$

The rate equation for this CEE mechanism is linear in $c_{\mathrm{O}}$ and $c_{\mathrm{R}}[5,6,7]$ :

$j_{\mathrm{F}}=-n F k_{\mathrm{f}}\left[c_{\mathrm{O}}-c_{\mathrm{R}} \exp (\phi)\right]$

with

$\phi=(n F / R T)\left(E-E^{\circ}\right)$

If all the steps are rate-controlling to some extent, the rate constant $k_{\mathrm{f}}$ should obey the expression

$\frac{1}{k_{\mathrm{f}}}=\frac{1}{k_{\mathrm{c}}}+\frac{\exp \left(\frac{1}{2} \alpha_{1} \phi\right)}{k_{\mathrm{s}, 1}}+\frac{\exp \left(\frac{1}{2}+\frac{1}{2} \alpha_{2}\right) \phi}{k_{\mathrm{s}, 2}}$

where, assuming symmetrical energy barriers for the single-electron transfers, $\alpha_{1}$ and $\alpha_{2}$ should be equal or close to 0.5. Curves b in Figs. 2 and 3 show a fit to eqn. (10) using the set of parameters given in ref. 6 . It was not possible to improve the fit by inserting other values for the potential-independent rate constants. However, a more satisfactory solution was found when we allowed the first term in eqn. (10) to be slightly potential dependent, i.e. $k_{\mathrm{c}}=k_{\mathrm{c}}^{0} \exp \left(-\alpha_{0} \phi\right)$. The best choice is $\alpha_{0}=0.06$, leading to curves a in Figs. 2 and 3, with the other parameters as summarized in Table 1 .

It may be noted that in fact this result is consistent with the result of the measurements at high Cd(II) concentration reported in Fig. 2 of ref. 6, which gave apparent Butler-Volmer behaviour in the very negative potential region with $\alpha=0.06$ and $k_{\mathrm{s}}\left(\equiv k_{\mathrm{c}}^{0}\right)$ equal to $0.2 \pm 0.1 \mathrm{~cm} \mathrm{~s}^{-1}$. Moreover, in Fig. 4 it can be seen that the $k_{\mathrm{f}}$ values obtained from our own admittance measurements are in quite good agreement with the $\ln k_{\mathrm{f}}$ vs. $E$ curve calculated from our model. Remarkably enough, this agreement is better than would be obtained using Bongenaar's $k_{\mathrm{f}}$ values, which are systematically higher than our present results. The origin of the discrepancy is as yet unclear, but could be due to former inaccurate data analysis. 


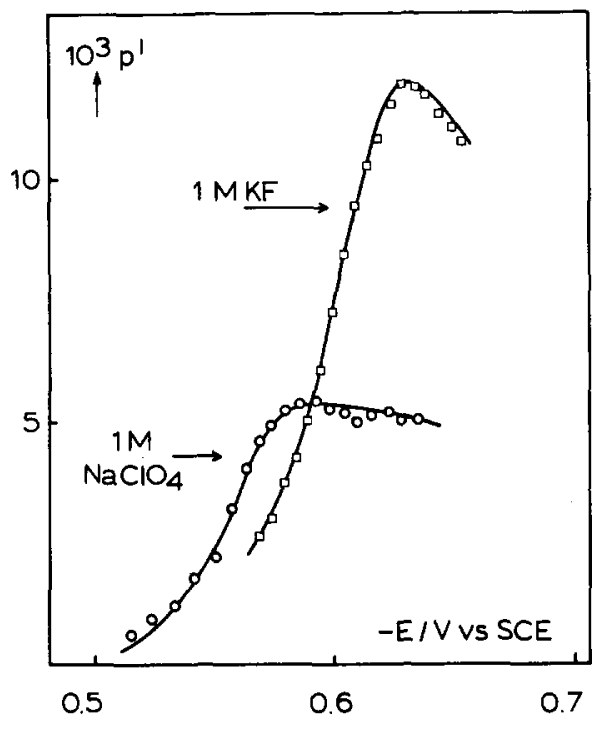

(a)

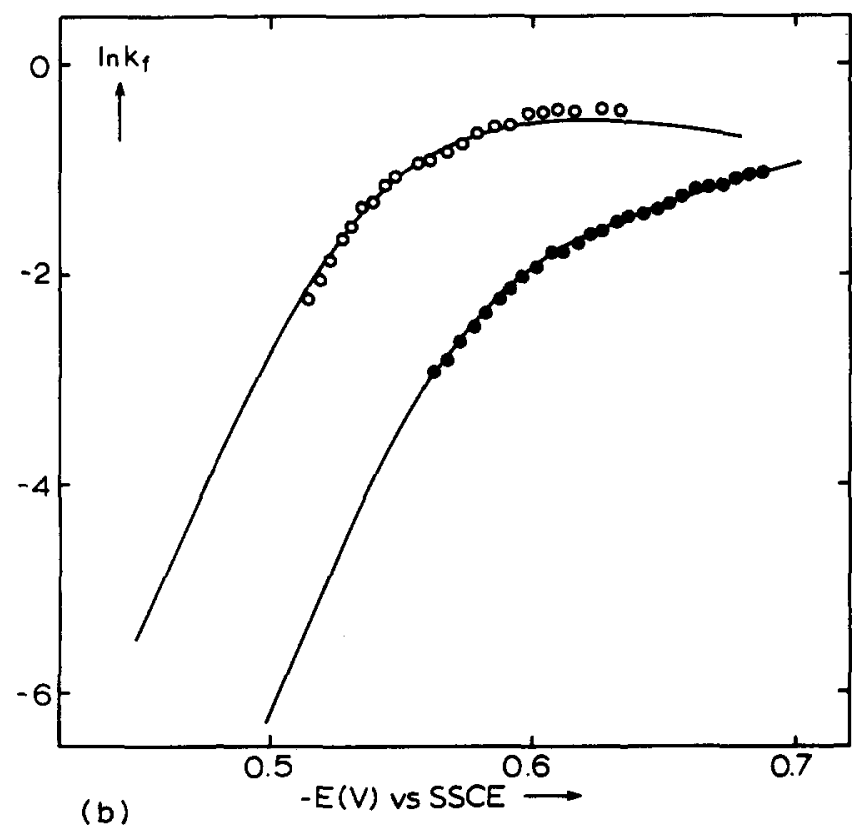

Fig. 4. (a) The irreversibility quotient $p^{\prime}$ obtained from admittance measurements for $2.5 \mathrm{~m} M \mathrm{Cd}(\mathrm{II})$ in 1 $M \mathrm{KF}$, and $4 \mathrm{mM} \mathrm{Cd}(\mathrm{II})$ in $0.5 \mathrm{M} \mathrm{NaClO}{ }_{4}+0.5 M \mathrm{HClO}_{4}$. (b) The forward rate constant of the $\mathrm{Cd}(\mathrm{II})$ reduction in $1 \mathrm{M} \mathrm{KF}$ and in $0.5 M \mathrm{NaClO}_{4}+0.5 \mathrm{M} \mathrm{HClO}_{4}$. (-) Results of demodulation experiments. $(\bullet, O)$ Results of admittance experiments $(\bullet=$ fluoride, $O=$ perchlorate). Note the larger potential range covered by the demodulation method. 
Finally, we tested the applicability to our demodulation data of the non-linear reaction mechanism, involving a dismutation step preceded by a chemical reaction instead of the second electron transfer:

$\begin{array}{lllll}\mathrm{Cd}(\mathrm{II}) & \rightleftarrows & \mathrm{Cd}(\mathrm{II})^{*} & \mathrm{R}_{\mathrm{c} 1} & \\ \mathrm{Cd}(\mathrm{II})^{*}+e^{-} & \rightleftarrows & \mathrm{Cd}(\mathrm{I}) & \mathrm{R}_{1} & \\ \mathrm{Cd}(\mathrm{I}) & \rightleftarrows & \mathrm{Cd}(\mathrm{I})^{*} & \mathrm{R}_{\mathrm{c} 2} & \\ 2 \mathrm{Cd}(\mathrm{I})^{*} & \rightleftarrows & \mathrm{Cd}(\mathrm{II})^{*}+\mathrm{Cd}(\mathrm{Hg}) & \mathrm{R}_{\mathrm{d}} \quad \text { (fast) }\end{array}$

Following the considerations in ref. 6 and the more general formalism in our theoretical paper [7], the rate equation for this CECd mechanism can be written in the rather simple form

$j_{\mathrm{F}}=-n F k_{\mathrm{f}}\left[c_{\mathrm{O}}^{p} c_{\mathrm{R}}^{q}-c_{\mathrm{O}}^{r} c_{\mathrm{R}}^{s} \exp (t \phi)\right]$

with, in this case, $p=1, q=0, r=s=t=\frac{1}{2}$ and

$\frac{1}{k_{\mathrm{f}}}=\frac{1}{k_{\mathrm{c}, 1}}+\frac{\exp \left(\frac{1}{2} \alpha_{\mathrm{l}} \phi\right)}{k_{\mathrm{s}, 1}}+\frac{\exp \left(\frac{1}{2} \phi\right)}{k_{\mathrm{c}, 2}}$

As mentioned in the introduction, this mechanism could not be ruled out on the basis of the admittance experiments. However, using the set of parameters giving the best fit to the $k_{\mathrm{f}}$ data in Fig. 4 (see Table 1) we obtained curves c shown in Figs. 2 and 3. The obvious conclusion is that the non-linear mechanism can be safely discarded in view of the results of the demodulation experiments.

\section{(IV.2) $\mathrm{Cd}(\mathrm{II})$ in $0.5 \mathrm{M} \mathrm{NaClO}_{4}+0.5 \mathrm{M} \mathrm{HClO}_{4}$}

The reduction of $\mathrm{Cd}(\mathrm{II})$ in perchlorate solutions has been studied several times with various methods $[1,2,16]$. So far, only standard rate constants $\left(k_{\mathrm{sh}}\right)$ and overall transfer coefficients $(\alpha)$ have been reported. From the compilation made by Tamamushi and Tanaka [1] it can be seen that the charge-transfer reaction is faster than with fluoride: $k_{\mathrm{sh}}=0.25-0.50 \mathrm{~cm} \mathrm{~s}^{-1}$ in $\mathrm{ClO}_{4}^{-}$, whereas $k_{\mathrm{sh}}=0.16 \pm 0.01 \mathrm{~cm} \mathrm{~s}^{-1}$ in $\mathrm{F}^{-}$(this work). The tabulated $\alpha$ values are mostly in between 0.1 and 0.25 , but extreme results, viz. $\alpha=0$ and $\alpha=0.68$, have also bee reported. This suggests that a more complex potential dependence of $k_{\mathrm{f}}$, similar to eqn. (10), exists.

Admittance measurements performed at $\mathrm{Cd}$ (II) concentrations of $1 \mathrm{~m} M$ and $4 \mathrm{~m} M$ yielded $p^{\prime}$ values in the potential region -0.520 to $-0.640 \mathrm{~V}$ vs. SSCE, which nicely brackets the half-wave potential $E_{1 / 2}^{\mathrm{r}} \doteq-0.569 \mathrm{~V}$ vs. SSCE. These results, together with the $p^{\prime}$ values for $1 M \mathrm{KF}$, are presented in Fig. 4a. The corresponding $k_{\mathrm{f}}$ values are shown in Fig. $4 \mathrm{~b}$. As in fluoride, the ln $k_{\mathrm{f}}$ vs. $E$ plot is significantly curved.

The demodulation components $I_{\mathrm{LF}}$ and $Q_{\mathrm{LF}}$ plotted vs. potential in Fig. 5 are largely similar in shape to those obtained in fluoride (see Fig. 2). The magnitude of the demodulation signals is considerably lower in perchlorate than in fluoride 
because of the proportionality to $C_{\mathrm{d}}^{-2}$, whereas $C_{\mathrm{d}}$ differs almost by a factor of 1.5 , see Fig. 1.

Due to the relatively high rate of the charge-transfer process only a small potential range is available where $S_{\mathrm{F}}^{*}$ can be obtained from a direct combination with admittance data $Y_{\mathrm{L}}^{\prime}, Y_{\mathrm{L}}^{\prime \prime}$ pertaining to the $1 \mathrm{~m} M \mathrm{Cd}(\mathrm{II})$ solution. These $S_{\mathrm{F}}^{*}$ values are represented in Fig. 6 as black circles. However, it was possible to extend
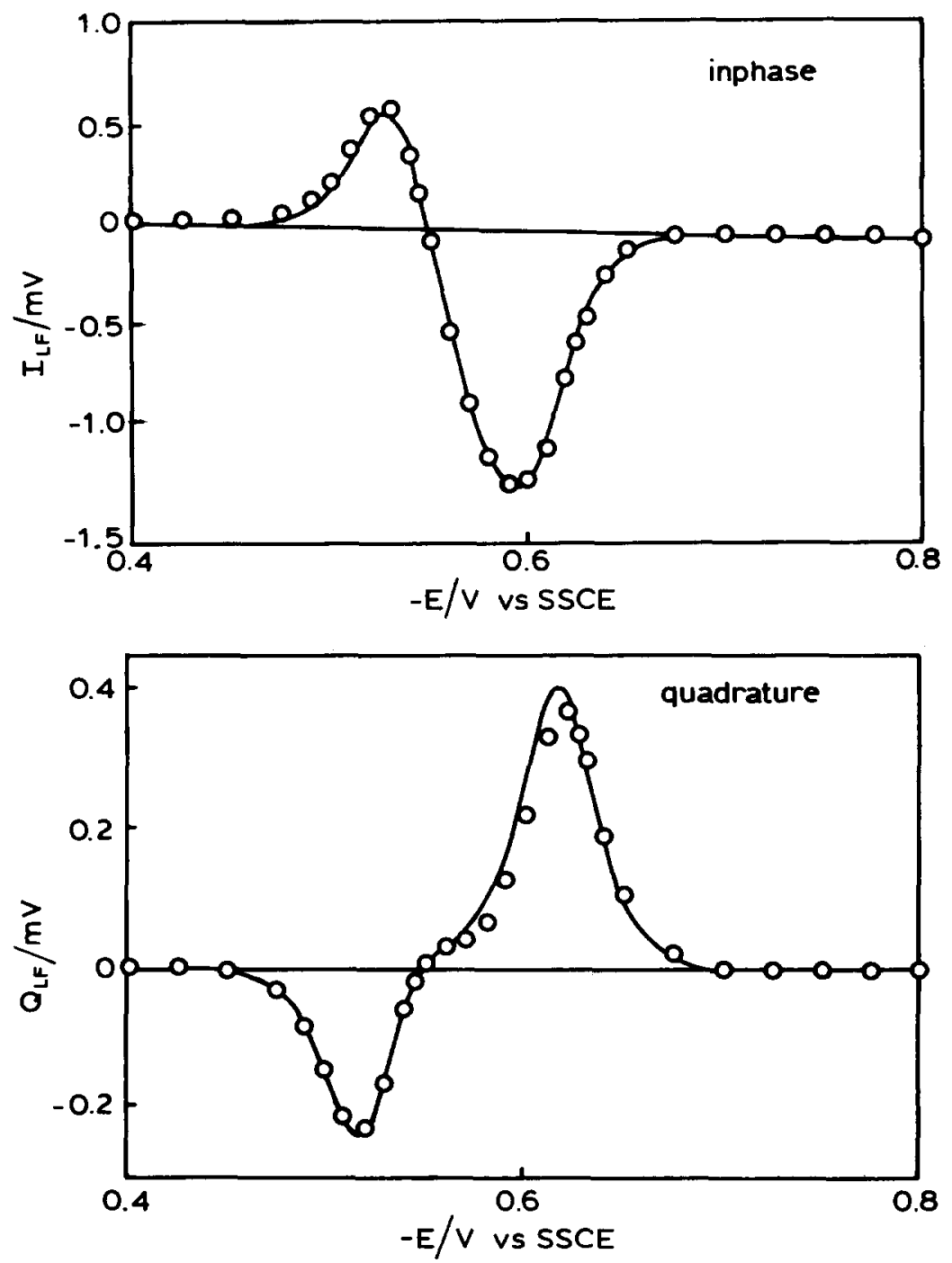

Fig. 5. Components of the demodulation voltage response for $1 \mathrm{~m} \mathrm{M} \mathrm{Cd(II)} \mathrm{in} 0.5 M \mathrm{NaClO}_{4}+0.5 M$ $\mathrm{HClO}_{4}$ - (O) Experimental. (——) Calculated from the parameters given in the text. Input parameters as in Fig. 2. 
the potential range employing the admittance analysis of the $4 \mathrm{~m} M \mathrm{Cd}(\mathrm{II})$ solution. From this analysis both $p^{\prime}$ and $\sigma$, the Warburg coefficient, are obtained. Since $p^{\prime}$ is concentration independent and $\sigma^{-1}$ (at fixed potential) is proportional to the bulk concentration, the admittance components pertaining to a concentration of $1 \mathrm{~m} M$ $\mathrm{Cd}$ (II) can be readily computed with the aid of eqn. (1). In this way the open circles in Fig. 6 were produced.

Again an attempt to fit the results to eqn. (10) with a potential-independent first term was unsatisfactory. The reason for this is most clearly seen in Fig. 6 where curve $b$ represents the best fit obtained with eqn. (10). Evidently the experimental $S_{\mathrm{F}}^{*}$ tends to go beyond the theoretical limit of -0.5 on extrapolation to more negative potential. This can only mean that the operational transfer coefficient $\left(\alpha=-\mathrm{d} \ln k_{\mathrm{f}} / \mathrm{d} \phi\right)$ is less than zero, at least in the negative potential range. Therefore, the first term in eqn. (10) was again replaced by a term $\exp \left(\alpha_{0} \phi\right) / k_{\mathrm{c}}^{0}$. Then quite a good agreement was obtained between the data points and the curves a

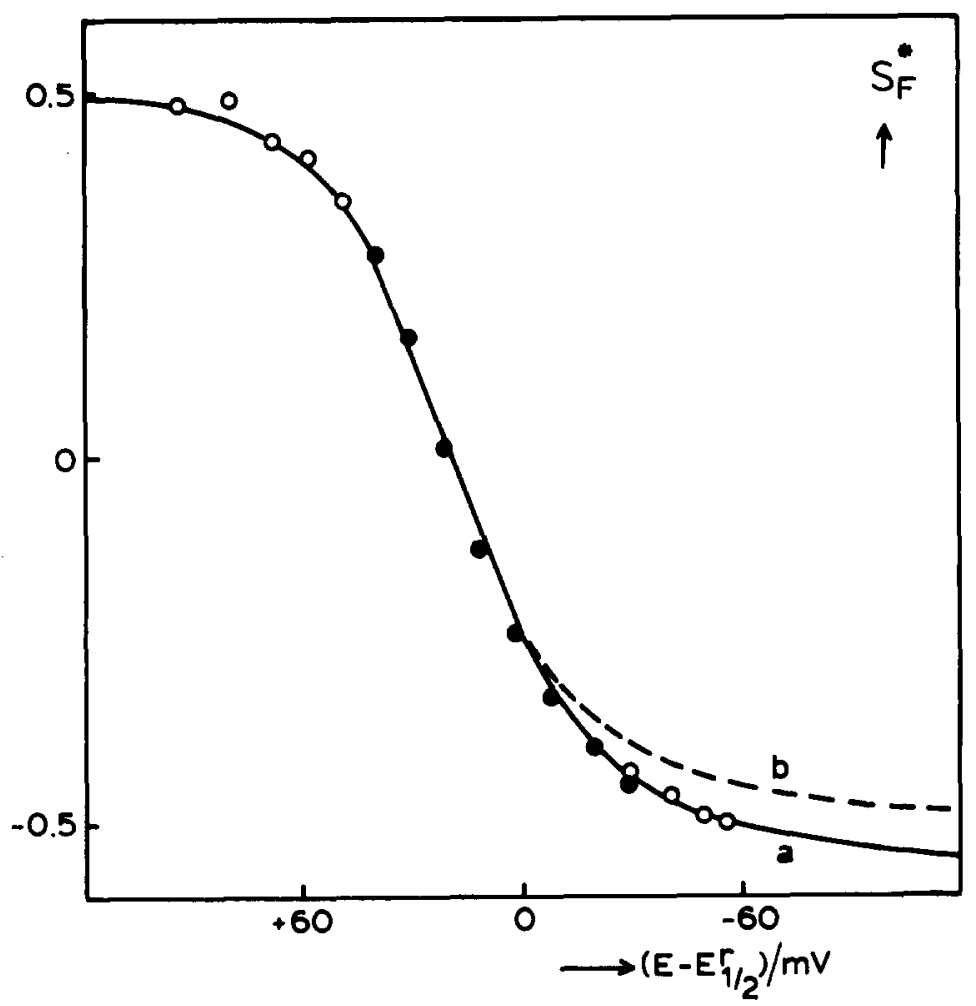

Fig. 6. $S_{\mathrm{F}}^{*}$ as a function of $E-E_{1 / 2}^{\mathrm{r}}$ derived from the data in Fig. 5 and the interfacial admittances $Y=Y^{\prime}+i Y^{\prime \prime}$ at $244 \mathrm{~Hz}$. (๑) Admittance measured at $1 \mathrm{~m} \mathrm{M} \mathrm{Cd(II).} \mathrm{(O)} \mathrm{Admittance} \mathrm{calculated} \mathrm{from} \mathrm{data}$ at $4 \mathrm{~m} \mathrm{M} \mathrm{Cd(II).} \mathrm{(-} \mathrm{Calculated} \mathrm{from} \mathrm{the} \mathrm{data} \mathrm{in} \mathrm{the} \mathrm{text.} \mathrm{(--} \mathrm{)} \mathrm{Best} \mathrm{fit} \mathrm{with} \mathrm{potential-independent}$ rate constant of the chemical step $\left(\alpha_{0}=0\right)$. 
in Figs. 5a, 5b and 6, which correspond to the following set of parameters:

$$
\begin{aligned}
& E_{1 / 2}^{r}=-0.569 \mathrm{~V} \text { vs. SSCE } D_{\mathrm{O}}=8 \times 10^{-6} \mathrm{~cm}^{2} \mathrm{~s}^{-1} \\
& E^{\circ}=-0.571 \mathrm{~V} \text { vs. SSCE } \quad D_{\mathrm{R}}=10.7 \times 10^{-6} \mathrm{~cm}^{2} \mathrm{~s}^{-1} \\
& k_{\mathrm{c}}^{0}=1.0 \mathrm{~cm} \mathrm{~s}^{-1} \quad \alpha_{0}=-0.07 \\
& k_{\mathrm{s}, 1}=1.1 . \mathrm{cm} \mathrm{s}^{-1} \quad \alpha_{1}=0.5 \\
& k_{\mathrm{s}, 2}=5 \mathrm{~cm} \mathrm{~s}^{-1} \quad \alpha_{2}=0.5
\end{aligned}
$$

Note that $E_{1 / 2}^{\mathrm{r}}$ and $D_{\mathrm{O}}$ are slightly different from the values mentioned in Section (II.1); the choices made here are essential to obtain a good fit on $I_{\mathrm{LF}}$ and $Q_{\mathrm{LF}}$.

The curve drawn in Fig. $4 \mathrm{~b}$ represents the $\ln k_{\mathrm{f}}$ vs. $E$ curve, composed after substitution of these parameters in eqn. (10). Again the agreement with the admittance results is remarkably good. The conclusion is therefore that the reduction mechanisms in perchlorate and fluoride solutions are the same.

\section{(IV.3) $\mathrm{Cd}(\mathrm{II})$ in $1 \mathrm{M} \mathrm{KCl}$}

The reduction rate of $\mathrm{Cd}$ (II) in $1 \mathrm{M} \mathrm{KCl}$ is known to be very fast: the most reliable standard rate constants $\left(k_{\mathrm{sh}}\right)$ reported vary from 1 to $4 \mathrm{~cm} \mathrm{~s}^{-1}[5,10,16,17]$. Although this variance could be considered to be within the inaccuracy inherent in such high values, it appears that there is a discrepancy between the results of different techniques. This was ascribed by Van der Pol et al. [5] to the possibility of a non-linear mechanism of the type ceCd which gave the best fit to their faradaic rectification experiments. On the other hand, the results of the admittance method applied by Bongenaar et al. [6] to the $\mathrm{Cd}(\mathrm{II})$ reduction in $x M \mathrm{KCl}+(1-x) M \mathrm{KF}$ strongly suggest that the reaction mechanism does not change on going from fluoride to chloride.

A closer inspection of carefully determined admittance data, however, revealed that the quantity $\omega^{1 / 2} / Y^{\prime}$ decreases slightly with increasing frequency instead of being constant as would be expected for such a reversible system [18]. It is not impossible, therefore, that adsorption of some $\mathrm{Cd}(\mathrm{II})$ species interferes with the analysis.

The demodulation signals we obtained (see Fig. 7) appear to confirm this surmise. The peaks in $I_{\mathrm{LF}}$ and $Q_{\mathrm{LF}}$ are extremely large, and moreover the data could not be adapted to any reasonable mechanism. Note that rather small peaks had to be expected, because of the large $C_{\mathrm{d}}$ values.

Although this was surprising at first sight, the evaluation of $S_{\mathrm{F}}^{*}$, represented in Fig. 8 , is most illumating: the experimental points greatly exceed the theoretical limits both at positive potentials $(+0.5)$ and negative potentials $(-0.5)$ and no tendency to bend to the horizontal plateaus is observed. The dashed curves in Fig. 7 represent the demodulation polarograms that would be observed in $1 \mathrm{M} \mathrm{KCl}$ if the $\mathrm{Cd}$ (II) reduction proceeded infinitely fast. Normally experimental peak heights cannot be larger than these "ac reversible" ones, as follows from the theoretical 

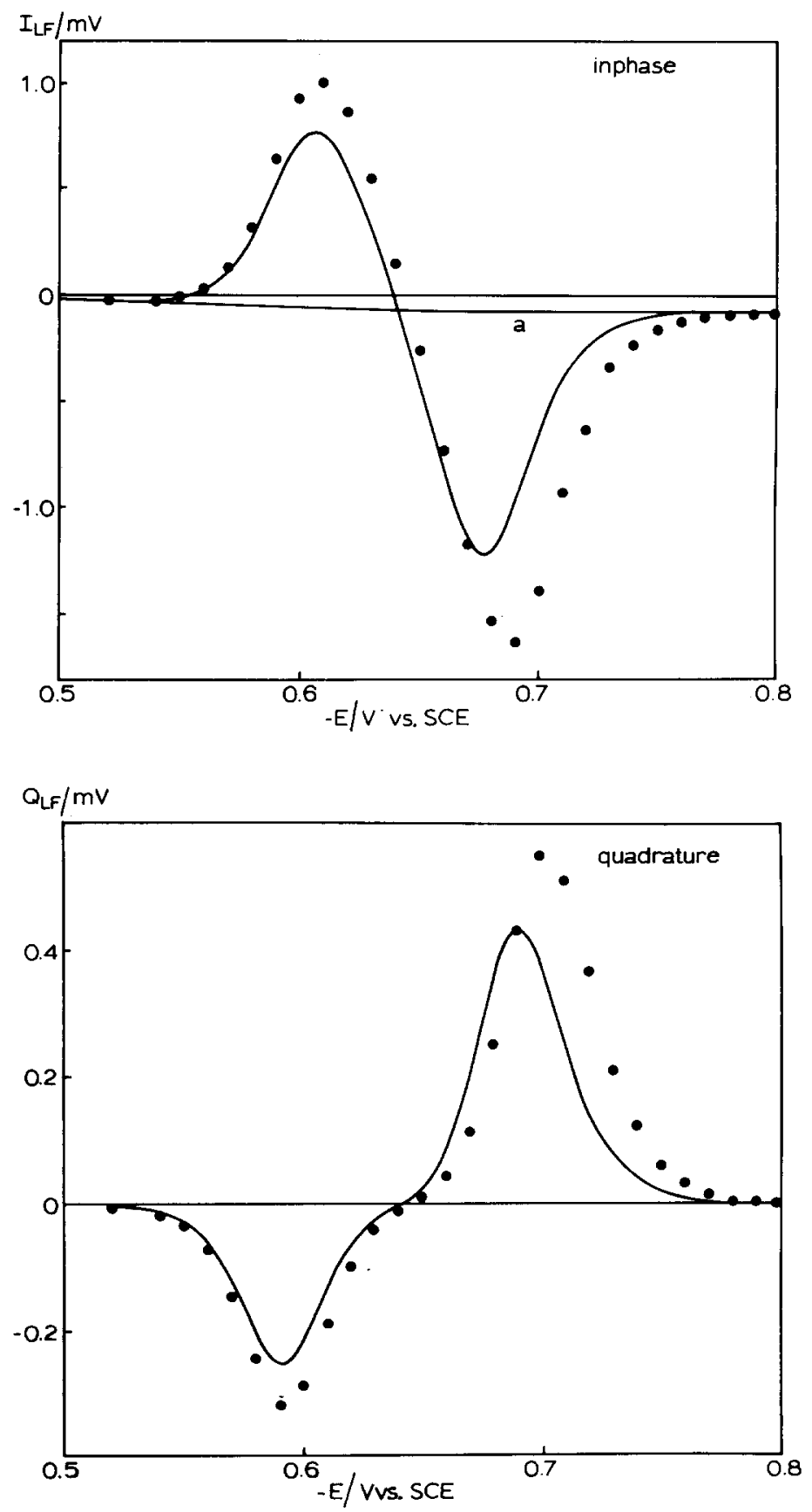

Fig. 7. Components of the demodulation voltage response for $1 \mathrm{~m} M \mathrm{Cd}(\mathrm{II})$ in $1 M \mathrm{KCl}$. (ө) Experimental. (- - Theoretical for infinitely high rate constants. 


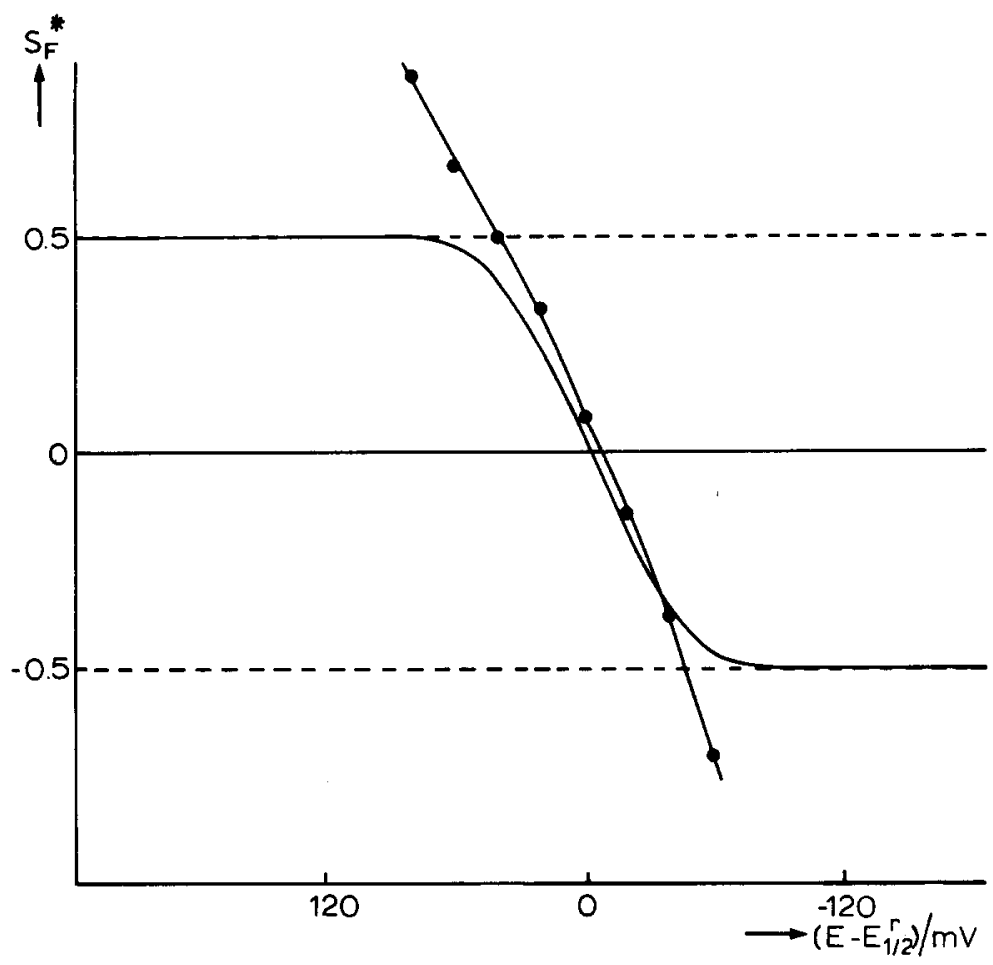

Fig. 8. (-๑) $S_{\mathrm{F}}^{*}$ as a function of $E-E_{1 / 2}^{\mathrm{r}}$ derived from the data in Fig. 7. ( $\longrightarrow$ ) Theoretical for infinitely high rate constants.

predictions discussed in ref. 9. We must therefore conclude that the demodulation results are not consistent with the theoretical expression derived so far on the assumption of Randles behaviour being obeyed.

\section{(V) DISCUSSION}

The high accuracy of the demodulation technique as well as the possibility of obtaining detailed information over a wide potential range enable us to determine the kinetic parameters describing a reaction mechanism with great precision. In addition, the theoretical sensitivity to possible non-linearity of a rate equation permits a distinction to be made between several (logical) mechanisms. The demodulation method being in a way complementary to the well-known admittance method, the combination of both proves to be a highly effective procedure for deciding the reaction mechanism in the case of the Cd(II) reduction in fluoride and perchlorate. Apart from this, the results obtained with the $1 M \mathrm{KCl}$ supporting electrolyte show that non-validity of Randles behaviour is evident from demodulation measurements more clearly than from admittance measurements [6]. This was also found in our study of the tris-oxalato $\mathrm{Fe}(\mathrm{III}) /$ tris-oxalato $\mathrm{Fe}(\mathrm{II})$ redox couple using both techniques [12]. 
The origin of the apparent potential dependence of the reaction $\mathrm{Cd}(\mathrm{II}) \rightleftarrows \mathrm{Cd}(\mathrm{II})^{*}$ in $1 M \mathrm{KF}$ might be explained as a consequence of the Frumkin effect. In other words, it will disappear if the Frumkin correction is applied. However, in the perchlorate medium the decrease of $\ln k_{\mathrm{f}}$ at negative potentials cannot be explained this way. It might be inferred that the slight specific adsorption of $\mathrm{ClO}_{4}^{-}$plays a role. It is most unlikely that the tendency of $k_{\mathrm{f}}$ to decrease with decreasing potential will continue beyond the accessible potential range: the $k_{\mathrm{f}}$ value would eventually become so small that the current density in a dc polarogram would no longer be diffusion controlled. In practice this is not observed.

There is a remarkable parallel between the fluoride and the perchlorate solutions with respect to the influence of the separate steps. In both media the preceding chemical reaction and the first electron transfer are simultaneously rate-determining at the reversible half-wave potential $E_{1 / 2}$. The second electron-transfer step is rate-determining at potentials in the anodic region. This can be seen in Fig. $4 \mathrm{~b}$, where the operational transfer coefficient $\alpha=-\mathrm{d} \ln k_{\mathrm{f}} / \mathrm{d} \phi$ is found to decrease from ca. 0.75 at $E \gg E_{1 / 2}$ via $0.2(\mathrm{KF})$ or $0.15\left(\mathrm{NaClO}_{4}\right)$ at $E=E_{1 / 2}$ to $0.06(\mathrm{KF})$ or $-0.07\left(\mathrm{NaClO}_{4}\right)$ at $E \ll E_{1 / 2}$. Note that the potential range covered by the admittance technique is rather restricted compared with the demodulation technique. Nevertheless, the $\ln k_{\mathrm{f}}$ plot derived from admittance measurements is significantly curved and this explains the discrepancies between standard rate constants and transfer coefficients previously reported in the literature, assuming Butler-Volmer behaviour. There is good reason to conclude that the results of the present work are reliable and self-consistent considered from the point of view that the potential dependency of the rate constant is governed primarily by the multi-step mechanism, whereas secondary effects may arise from e.g. double layer structure changing with potential.

Yet the results have led to some questions that need to be solved before our understanding of the kinetics of the $\mathrm{Cd}(\mathrm{II})$ reduction can be regarded as complete. Firstly, we feel that an identification and further description of the so-called "preceding chemical step" are very necessary. Secondly, its weak potential-dependence should be explained. The values of its rate constant obtained in fluoride and perchlorate solutions are remarkably close, which is a good argument to reject an involvement of $\mathrm{F}^{-}$ions and to think of a common origin of the chemical step.

Finally, no second-order theory is available with which an analysis can be made to account for reactant adsorption. Such a theory should be derived following routes analogous to those for the case of simple Randles behaviour [7,9,19], but starting with more complex boundary conditions which include surface excesses of reactants in the mass balance equations as well.

Work in the directions indicated is being started.

\section{ACKNOWLEDGEMENTS}

The experimental contributions of Dr. R. Andreu, J.M. Oostveen, M. Saakes and G. Jongert are gratefully acknowledged. 


\section{REFERENCES}

1 N. Tanaka and R. Tamamushi, Electrochim. Acta, 9 (1964) 963;

R. Tamamushi, Kinetic Parameters of Electrode Reactions of Metallic Compounds, IUPAC additional publication, Butterworths, London, 1975.

2 J.K. Frischmann and A. Timnick, Anal. Chem., 13 (1967) 507.

3 B. Lovreček and N. Marinzić, Electrochim. Acta 11 (1966) 237.

4 T. Biegler, E. Gonzalez and R. Parsons, Collect. Czech. Chem. Commun., 36 (1971) 414.

5 F. van der Pol, M. Sluyters-Rehbach and J.H. Sluyters, J. Electroanal. Chem., 58 (1975) 177.

6 C.P.M. Bongenaar, A.G. Remijnse, M. Sluyters-Rehbach and J.H. Sluyters, J. Electroanal. Chem., 111 (1980) 139, 155.

7 J. Struijs, M. Sluyters-Rehbach and H.J. Sluyters, J. Electroanal. Chem., 171 (1984) 157.

8 F. van der Pol, M. Sluyters-Rehbach and J.H. Sluyters, J. Electroanal. Chem., 62 (1975) 281.

9 J. Struijs, M. Sluyters-Rehbach and J.H. Sluyters, J. Electroanal. Chem., 143 (1983) 37, 61.

10 H.P. van Leeuwen and J.H. Sluyters, J. Electroanal. Chem., 39 (1972) 233.

11 C.P.M. Bongenaar, M. Sluyters-Rehbach and J.H. Sluyters, J. Electroanal., Chem., 109 (1980) 23.

12 J. Struijs, M. Sluyters-Rehbach and J.H. Sluyters, J. Electroanal. Chem., 146 (1983) 263.

13 J. Newman, J. Electroanal. Chem., 15 (1969) 309.

14 H. Gerischer, Z. Phys. Chem., 198 (1951) 286.

15 G.C. Barker, A.W. Gardner and M.J. Williams, J. Electroanal. Chem., 41 (1973) App. 1.

16 R. de Leeuwe, M. Sluyters-Rehbach and J.H. Sluyters, Electrochim. Acta, 14 (1969) 1183.

17 G. Salié, Z. Phys. Chem. (Leipzig), 244 (1970) 1.

18 M. Sluyters-Rehbach and J.H. Sluyters in A.J. Bard (Ed.), Electroanalytical Chemistry, Vol. 4, Marcel Dekker, New York, 1970, pp. 1-128.

19 M. Sluyters-Rehbach, J. Struijs and J.H. Sluyters, J. Electroanal. Chem., 100 (1979) 607. 